Global Sustainability

cambridge.org/sus

\section{Research Paper}

Cite this article: Ivanova D, Wood R (2020). The unequal distribution of household carbon footprints in Europe and its link to sustainability. Global Sustainability 3, e18, 1-12. https://doi.org/10.1017/sus.2020.12

Received: 25 July 2019

Revised: 3 June 2020

Accepted: 3 June 2020

Keywords:

adaptation and mitigation; ecology and biodiversity; energy; human behaviour; policies; politics and governance

Author for correspondence:

Dr Diana Ivanova,

E-mail: d.ivanova@leeds.ac.uk

\title{
The unequal distribution of household carbon footprints in Europe and its link to sustainability
}

\section{Diana Ivanova ${ }^{1,2}$ (1) and Richard Wood ${ }^{2}$}

${ }^{1}$ School of Earth and Environment, University of Leeds, Leeds, UK and ${ }^{2}$ Industrial Ecology Programme, Norwegian University of Science and Technology, Trondheim, Norway

\section{Non-technical summary}

The distribution of household carbon footprints is largely unequal within and across countries. Here, we explore household-level consumption data to illustrate the distribution of carbon footprints and consumption within 26 European Union countries, regions and social groups. The analysis further sheds light on the relationships between carbon footprints and socially desirable outcomes such as income, equality, education, nutrition, sanitation, employment and adequate living conditions.

\section{Technical summary}

We need a good understanding of household carbon distributions in order to design equitable carbon policy. In this work, we analyse household-level consumer expenditure from 26 European Union (EU) countries and link it with greenhouse gas (GHG) intensities from the multiregional input-output database EXIOBASE. We show carbon footprint distributions and elasticities by country, region and socio-economic group in the context of per capita climate targets. The top $10 \%$ of the population with the highest carbon footprints per capita account for $27 \%$ of the EU carbon footprint, a higher contribution to that of the bottom $50 \%$ of the population. The top $1 \%$ of EU households have a carbon footprint of $55 \mathrm{tCO}_{2} \mathrm{eq} / \mathrm{cap}$. The most significant contribution is from air and land transport, with $41 \%$ and $21 \%$ among the top $1 \%$ of EU households. Air transport has a rising elasticity coefficient across EU expenditure quintiles, making it the most elastic, unequal and carbon-intensive consumption category in this study. Only $5 \%$ of EU households live within climate targets, with carbon footprints below $2.5 \mathrm{tCO}_{2} \mathrm{eq} / \mathrm{cap}$. Our analysis points to the possibility of mitigating climate change while achieving various well-being outcomes. Further attention is needed to limit trade-offs between climate change mitigation and socially desirable outcomes.

\section{Social media summary}

EU top $1 \%$ of households emit 22 times the per capita climate targets. Only 5\% of EU households live within the targets. (c) The Author(s), 2020. Published by Cambridge University Press. This is an Open Access article, distributed under the terms of the Creative Commons Attribution licence (http://creativecommons.org/licenses/by/4.0/), which permits unrestricted re-use, distribution, and reproduction in any medium, provided the original work is properly cited.

\section{CAMBRIDGE} UNIVERSITY PRESS

\section{Introduction}

Emission pathways for global warming of between $1.5^{\circ} \mathrm{C}$ and $2.0^{\circ} \mathrm{C}$ require steep reductions in global net emissions, reaching 25-45\% in 2030 (compared to 2010 levels), with net-zero emissions by 2050-2070 (Masson-Delmotte et al., 2018). On a per-capita basis, global emissions therefore need to go down to 2.5-3.3 $\mathrm{tCO}_{2}$ per capita in 2030 (Global Carbon Project, 2018; UN, 2017) or less (Girod et al., 2014; O’Neill et al., 2018; Tukker et al., 2016). These reductions are necessary to halt climate change and would require rapid and far-reaching changes in all aspects of society, including production and consumption practices.

The current distribution of greenhouse gas (GHG) emissions is largely unequal within (Chancel \& Piketty, 2015; Otto et al., 2019; Wiedenhofer et al., 2016) and across countries (Ivanova et al., 2016). The top $10 \%$ of GHG emitters make up $34-45 \%$ of annual GHG emissions globally (Chancel \& Piketty, 2015; Hubacek et al., 2017). The carbon footprint of a typical super-rich household of two is estimated to be about $130 \mathrm{tCO}_{2} \mathrm{eq}$ (Otto et al., 2019), compared to a world average of $3.4 \mathrm{tCO}_{2} \mathrm{eq} / \mathrm{cap}$ in 2011 (Stadler et al., 2018). About a fifth of the top $10 \%$ of world emitters are located in the European Union (EU) (Chancel \& Piketty, 2015). The EU has an average carbon footprint of $8.2 \mathrm{tCO}_{2} \mathrm{eq} / \mathrm{cap}$ and constitutes $22 \%$ of global GHG emissions (Ivanova et al., 2016). 
A large body of literature on household environmental impacts exists, applying various perspectives and methods to study the resource use and wastes associated with consumption (Di Donato et al., 2015; Dubois et al., 2019; Niamir, 2019; Rai \& Henry, 2016). Prior studies have linked household expenditure surveys with environmental intensities to show the distribution of environmental footprints (Di Donato et al., 2015; Ivanova et al., 2017; Wiedenhofer et al., 2018) and the effect of (prospective) environmental policies on different household groups (Cullenward et al., 2016; Melnikov et al., 2017; Rausch et al., 2011). Recent developments address regional and urban sustainability (Di Donato et al., 2015), with existing studies focusing on a single country or region (Büchs \& Schnepf, 2013; Gill \& Moeller, 2018; Girod \& De Haan, 2010) or aggregated units of analysis such as income groups (Steen-Olsen et al., 2016; Wiedenhofer et al., 2016), regions and countries (Dubois et al., 2019). For example, an analysis of the carbon footprints of 177 regions highlights the spatial heterogeneity across the EU regions (Ivanova et al., 2017). While the contribution of the EU to global emissions is substantial, a detailed analysis of its carbon footprint distribution is largely missing.

To our knowledge, this is the first study to communicate carbon footprint distributions of the EU based on household-level consumption data (micro-data). The analysis covers 275,246 household surveys of between 51 and 63 different consumption categories from $26 \mathrm{EU}$ countries, which is by far the most extensive to our knowledge. We combine the use of expenditure data with GHG emission intensities derived through multiregional input-output (MRIO) analysis building on prior regional-level analysis (Ivanova et al., 2017). We capture differences in consumption and carbon trends between the highest and the lowest EU emitters and compare them to a per capita carbon target level of $2.5 \mathrm{tCO}_{2} \mathrm{eq} / \mathrm{cap}$.

Climate change and mitigation policies have a varying impact on different segments of the population, with the consumption, livelihoods and well-being of the poorest often being most drastically affected (Rao et al., 2017). Having a distributional perspective is essential for the design of mitigation policies prioritizing wellbeing, social protection and access to resources within planetary boundaries (Cullenward et al., 2016; Rao et al., 2017; Roberts et al., 2020). At the same time, distributional perspectives remain hugely underexplored (Rao et al., 2017). We discuss the policy implications of the EU consumption distribution for environmental and social outcomes.

Our study makes a contribution in three main ways. Firstly, it offers an overview of the carbon (and consumption) inequality in the EU and across countries, regions and social groups. Secondly, it explores the consumption trends of various household groups and discusses the carbon distribution by consumption category. Thirdly, it analyses the relationships between carbon footprints and social indicators within EU countries. We highlight the strong links between the consumption distribution and various social and environmental outcomes. Understanding these links is critical for achieving well-being within planetary boundaries.

\section{Methods}

\subsection{Household budget surveys}

Consumer expenditure data at the household level were collected from Eurostat and national statistics institutes in the form of household budget surveys (HBSs) for the year 2010. This is the latest harmonized dataset that is available at the moment of publication of our analysis. Supplementary Information (SI) 1 and the EU quality report on the 2010 wave (Eurostat, 2015) provide more detail on sample sizes, response rates, recording period and expenditure detail. This analysis includes HBSs from Belgium (BE), Bulgaria (BG), Cyprus (CY), Czech Republic (CZ), Germany (DE), Denmark (DK), Estonia (EE), Spain (ES), Finland (FI), France (FR), Greece (GR), Croatia (HR), Hungary (HU), Ireland (IE), Italy (IT), Lithuania (LT), Luxembourg (LU), Latvia (LV), Malta (MT), Poland (PL), Portugal (PT), Romania (RO), Sweden (SE), Slovenia (SI), Slovakia (SK) and the United Kingdom (GB).

The HBSs have highly a harmonized consumption structure (based on Eurostat's Classification of Individual Consumption by Purpose (COICOP)) and year coverage (i.e., 2010 wave) (Eurostat, 2015), although some differences in the survey design and methodology remain.

Households were asked to maintain detailed expenditure diaries over a fixed period of time (generally two weeks). In addition to the expenditure diaries, HBSs include interviews collecting information about regular expenditure such as rents and energy bills and infrequent larger purchases for up to one year retrospectively (Eurostat, 2015). Sharing common accommodation and expenses is central to the definition of a household for all HBSs. We derived per capita expenditure and footprints by applying the real household count with the same weights to children and adults.

\subsection{Harmonization of HBSs and EXIOBASE}

The use of environmentally extended MRIO analysis for quantifying household environmental impacts to produce top-down carbon footprint estimates is quite common (Di Donato et al., 2015; Ivanova et al., 2017; Steen-Olsen et al., 2016). The InputOutput Expenditure (IO-Expenditure; Di Donato et al., 2015) approach (also referred to as Consumer Expenditure Surveys Multiregional Input-Output (CES-MRIO) matching; Ivanova et al., 2017; Steen-Olsen et al., 2016) combines survey expenditure with carbon intensities from a MRIO model, which encompasses the whole economy providing goods and services to final demand.

The product-level carbon intensities in this work were derived from the EXIOBASE 3.6 database (Stadler et al., 2018). EXIOBASE has a high sectoral detail and a wide range of environmental and social satellite accounts (Wood et al., 2015), and version 3.6 provides input-output tables ranging from 1995 to 2016 for 44 countries (including 28 EU members) and 5 rest-of-the-world regions. Carbon footprints were calculated using the Global Warming Potential 100 (GWP100) metric communicating the amount of $\mathrm{CO}_{2}, \mathrm{CH}_{4}, \mathrm{~N}_{2} \mathrm{O}$ (from combustion and non-combustion) and $\mathrm{SF}_{6}$ in $\mathrm{kgCO}_{2}$-equivalents per year (Solomon et al., 2007). SI1 and the Supplementary Spreadsheet provide more details on the harmonization procedure between HBSs and EXIOBASE. We focused our analysis solely on household expenditure, thus excluding other final demands such as gross capital formation and governmental spending. Therefore, we quantified the household carbon footprint, referred to as the carbon footprint (CF) from here onwards.

Despite the large sample sizes, it is common to find significant differences between total expenditure as reported in HBSs and as estimated in national accounts. Prior studies have discussed the importance of survey under-reporting (e.g., with hospitality and 'discretionary' expenditure often underestimated in surveys) (Isaksen \& Narbel, 2017). Furthermore, HBSs generally record 
more expenditure on food and non-alcoholic beverages, housing, water, electricity, gas and other fuels compared to the national accounts (Eurostat, 2015; Statistics Explained, 2019), which matches our over-reporting adjustments in these sectors. The analysis of extremes may suffer from under-reporting at the top of the distribution (Chancel \& Piketty, 2015; Eurostat, 2015), thus underestimating the top and the mean expenditure. We estimated under- and over-spending on average by country and proportionally reallocated it to households.

\subsection{Indirect and direct GHG emissions}

We converted survey expenditure from purchaser's prices or the price paid by final consumers to basic prices $(b p)$ in order to match with EXIOBASE. We utilized transport, trade and tax layers, relocating the trade and transport costs from final products to the respective sectors. We introduced a function for this conversion $f$, described elsewhere (Steen-Olsen et al., 2016).

Direct GHG emissions occur during the use phase of products. We adopted direct emission intensities by products and countries measured in $\mathrm{kgCO}_{2} \mathrm{eq} / \mathrm{EUR}$ in $b p$, so that the amount of direct emissions was proportionate to the household spending on the product. For products with no (or very low) household spending, we adopted a fixed amount per capita.

We adopted a climate target of $2.5 \mathrm{tCO}_{2} \mathrm{eq} / \mathrm{cap}$ by 2030 , which is consistent with emission pathways limiting global warming to $1.5^{\circ} \mathrm{C}$ (Masson-Delmotte et al., 2018). Prior studies discuss per capita climate targets of 1.6-3.3 $\mathrm{tCO}_{2} \mathrm{eq} / \mathrm{cap}$ (Bjørn et al., 2018; Girod et al., 2014; Global Carbon Project, 2018; O'Neill et al., 2018; Tukker et al., 2016; UN, 2017). The time horizon for such a budget is critical, as essentially global emissions need to go down to net-zero (Masson-Delmotte et al., 2018).

\subsection{Statistical analysis and linking to social outcomes}

Expenditure elasticities (referred to as 'elasticities' hereafter) measure the responsiveness of expenditure on a certain product to a unit change in total expenditure. High elasticities of a product signal an increasing proportion of expenditure on the product with rising total expenditure, and these are common for non-necessities. Low elasticities are common for the consumption of necessities. A significant change in elasticities may reflect the shift from basic to discretionary spending (Rao \& Baer, 2012), or even conspicuous consumption. For example, food-related expenditure elasticities naturally decrease for higher-expenditure quintiles across EU countries, reflecting the decrease in utility from allocating more expenditure towards food consumption. Similarly, lowincome countries have a higher elasticity of food products than countries with higher income levels (Rao \& Baer, 2012).

We also explore the link between GHG emissions and socially desirable outcomes (Table 1). We based the social outcomes on multidimensional indicators for a safe and just space (O'Neill et al., 2018) and poverty measurement (Rao et al., 2017).

\section{Results}

\subsection{Carbon footprint distribution in the $E U$}

The top $10 \%$, middle $40 \%$ and bottom $50 \%$ of the population in terms of CF per capita contribute $27 \%, 47 \%$ and $26 \%$ of the EU total CF, respectively (Figure 1, left). That is, the top $10 \%$ of the EU population have a higher emission share than the bottom
$50 \%$. The top $1 \%$ of the EU population have a CF share as high as the bottom $18 \%$ combined, or about $6 \%$ of EU total emissions. These results are adjusted for the variation in household sizes by different emitting groups.

As household sizes among the groups vary substantially, the carbon distribution of the top $10 \%$, middle $40 \%$ and bottom $50 \%$ of EU households is very different (Figure 1, right). The top $10 \%$ of households contribute $19 \%$ of the EU CF with an average household size of 1.7 members. The share of the middle $40 \%$ and bottom $50 \%$ of households amounts to $43 \%$ and $38 \%$. Their average household sizes correspond to 2.1 and 2.6 members, respectively. As HBSs collect expenditures and weights per households, from here onwards we discuss results by households (corresponding to Figure 1, right). 'EU top 1\%' and 'EU top 10\%' refer to the $1 \%$ and $10 \%$ of EU households with the highest CF per capita, while 'EU bottom 50\%' refers to the 50\% of EU households with the lowest CF per capita. The rest of EU households fall within 'EU middle 40\%'.

High emitters from all EU countries are among the EU top $10 \%$ emitters (Table 2). These households have an average CF of $23 \mathrm{tCO}_{2} \mathrm{eq} / \mathrm{cap}$ (Figure 1) and a minimum CF of $15 \mathrm{tCO}_{2} \mathrm{eq} / \mathrm{cap}$. $\mathrm{DE}, \mathrm{GB}$ and IT contribute to the highest share of EU emissions - $4 \%, 4 \%$ and 3\%, respectively. As much as $36 \%$ of Luxembourg's households enter the EU top 10\%, which is the highest relative share among EU countries.

The average $\mathrm{CF}$ of the EU middle $40 \%$ emitters amounts to $10 \mathrm{tCO}_{2} \mathrm{eq} / \mathrm{cap}$ (Figure 1), with CFs between 7 and $15 \mathrm{tCO}_{2} \mathrm{eq} / \mathrm{cap}$. The average $\mathrm{CF}$ of the $\mathrm{EU}$ bottom $50 \%$ emitters amounts to $5 \mathrm{tCO}_{2} \mathrm{eq} / \mathrm{cap}$. This is about 5 times lower than that of the EU top $10 \%$ average and 12 times lower than that of the EU top $1 \%$.

The ranges in Figure 2 describe how concentrated the CF is within countries. Means are higher than medians for all countries, pointing to a right-skewed carbon distribution. Within countries, the top $1 \%$ of households have CFs between 15.0 (HR) and 48.3 (GR) $\mathrm{tCO}_{2}$ eq/cap, while the top $10 \%$ have CFs between 7.3 (HR) and $26.4(\mathrm{LU}) \mathrm{tCO}_{2} \mathrm{eq} / \mathrm{cap}$ (Figure 3). The highest share of CF below $2.5 \mathrm{tCO}_{2} \mathrm{eq} / \mathrm{cap}$ is noted in Romania at about $53 \%$. Other countries with a share of low-carbon households above $20 \%$ include Hungary, Latvia and Croatia. Conversely, countries such as Germany, Ireland, Greece and Luxembourg have less than $1 \%$ of households within climate targets.

Another way of measuring carbon inequality is through CF Ginis (i.e., carbon concentration indices). RO, BG and PL stand out with the highest CF Ginis, at between 0.42 and 0.45 , signalling their relatively unequal distribution of CFs. Even large geographical regions have more equal carbon distributions compared to countries (SI4). This is especially the case for Bulgaria and Poland, where regional Ginis drop to $0.25-0.34$. At the other end, Czech Republic, Slovakia and Germany have the most equal carbon distributions, with CF Ginis below 0.3.

\subsection{Carbon footprints by consumption category, expenditure and income quintiles}

The EU top $10 \%$ households have a carbon intensity at $0.86 \mathrm{kgCO}_{2}$ eq/EUR on average, while that of the EU top $1 \%$ is at $0.95 \mathrm{kgCO}_{2} \mathrm{eq} / \mathrm{EUR}$ on average. For comparison, the average EU carbon intensity is about $0.7 \mathrm{kgCO}_{2}$ eq/EUR. The highest emitters are associated with larger shares of land and air travel GHG emissions (Figure 3). Transport use has the highest carbon intensity among the consumption categories (SI4) and shows a stable increase with expenditure and income (Figure 4). Those with the 
Table 1. Socially desirable outcomes and definitions measured on a household level.

\begin{tabular}{|c|c|}
\hline Socially desirable outcomes & Definitions \\
\hline Income & Annual net household income in EUR per capita including non-monetary remunerations and excluding income tax \\
\hline $\begin{array}{l}\text { Risk of poverty and social } \\
\text { exclusion }\end{array}$ & $\begin{array}{l}\text { Below Eurostat's threshold for risk of poverty and social exclusion set at } 60 \% \text { of the national median disposable income } \\
\text { (Eurostat, 2017) (dummy variable) }\end{array}$ \\
\hline Fuel poverty & $\begin{array}{l}\text { High share of energy expenditure, where households under fuel poverty spend more than } 10 \% \text { of their household income } \\
\text { on energy costs at an income level below the national median level. Here, we aim to combine the UK's old and new fuel } \\
\text { poverty definitions as a way to lessen some of the issues associated with a purely 'low-income, high-cost' measure of fuel } \\
\text { poverty (for a critical analysis, see Middlemiss, 2017) }\end{array}$ \\
\hline Employment & Households receiving unemployment benefits as a main source of income (dummy variable) \\
\hline Education & $\begin{array}{l}\text { Average educational level of the adults based on the International Standard Classification of Education (ISCED) Scale } \\
\text { (UNESCO, 2012): } 0=\text { no formal education or below ISCED } 1 ; 1=\text { primary education; } 2=\text { lower secondary education; } 3=\text { upper } \\
\text { secondary education; } 4=\text { post-secondary non-tertiary education; } 5=\text { tertiary education first stage; } 6=\text { tertiary education } \\
\text { second stage }\end{array}$ \\
\hline Nutrition & $\begin{array}{l}\text { Consumption (annual expenditure in EUR) of fruits and vegetables. While there are more aspects to good nutrition, fruit } \\
\text { and vegetable intake is associated with reduced risk of non-communicable diseases, improved bone health and reduced } \\
\text { likelihood of unhealthy weight gain (European Commission, 2019) }\end{array}$ \\
\hline
\end{tabular}

(a)

EU individuals (adjusted by household size)

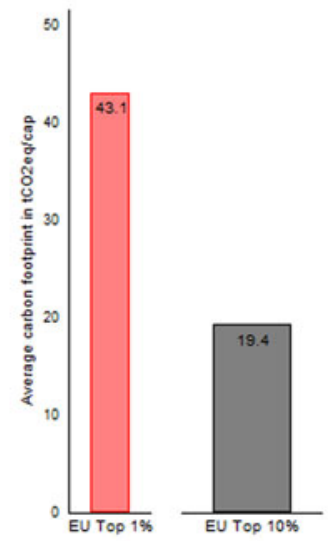

(b)

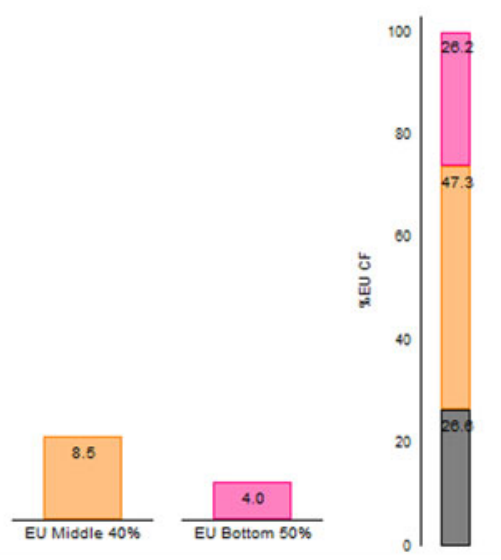

\section{EU households}

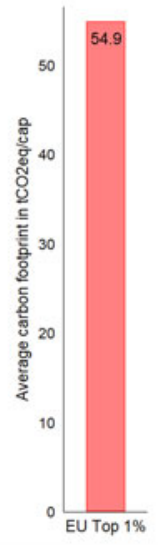

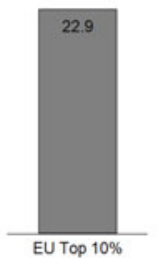
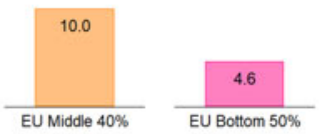

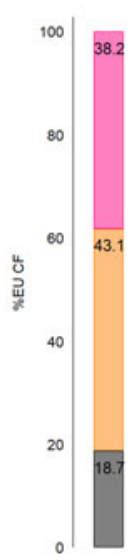

Fig. 1. Carbon footprint (CF) distribution by European Union (EU) individuals (adjusted by household size) on the left and by EU households on the right. 'EU Top $10 \%$ ' refers to the $10 \%$ of the EU population with the highest CFs per capita on the left plot and the $10 \%$ of households with the highest CFs per capita on the right plot. EU household weights applied.

highest CFs also have the highest expenditure and income levels, with a stronger correlation with expenditure (Figure 4).

The majority of GHG emissions of the top EU emitters are transport-related. In particular, air travel drives a $\mathrm{CF}$ of $22.6 \mathrm{tCO}_{2}$ eq/cap among the EU top $1 \%$ households, which is about $41 \%$ of their total contribution. It is the EU top $10 \%$ of households that fly, with an average air travel $\mathrm{CF}$ of the rest of the population below $0.1 \mathrm{tCO}_{2}$ eq/cap. The CF associated with air travel increases with rising expenditure and income (Figure 4). In fact, air travel is by far the most elastic consumption in the EU, with an expenditure elasticity of 1.5; this suggests that, as total expenditure doubles, the expenditure on air travel increases by $150 \%$ (Figure 5). The consumption category has a rising elasticity with expenditure quintile, reaching 2.0-2.7 among the highest spenders. Whilst the expenditure effect is strong, there are many households with high expenditure that avoid air travel. The lowest-expenditure quintile has an insignificant coefficient, which confirms that an increase in total spending does not result in an increase in flying among the lowest spenders. This confirms air travel as a highly carbon-intensive luxury (Oswald et al., 2020).

The trend of decreasing elasticity with rising total spending is generally present across categories, except for air travel (Figure 5). Our findings point to important expenditure thresholds for low-spending groups and decreasing elasticities for higher spenders across the consumption categories, signalling diminishing utility from further consumption of that good (Rao \& Baer, 2012). In the case of air travel, we note an increasing elasticity and hence a rising shift of expenditure towards this consumption category with rising total spending.

Land travel is associated with some of the highest consumption shares among the EU top emitters (Figure 3) and spenders (Figure 4). Land travel (purchase of vehicles, transport fuels and services) drives $32 \%$ of the CF of the top $10 \%$, making it the consumption category with the highest contribution among the biggest emitters. Nevertheless, the transport share of the lowest expenditure quintile is not negligible, with a relative importance of about $20 \%$, only below basic needs such as food and housing (Figure 4). 
Table 2. Share of European Union (EU) carbon footprint (CF) and households by country and emitting group.

\begin{tabular}{|c|c|c|c|c|c|c|}
\hline & \multicolumn{3}{|c|}{ Share of EU CF } & \multicolumn{3}{|c|}{ Share of households } \\
\hline & EU top $10 \%$ & EU middle $40 \%$ & EU bottom $50 \%$ & EU top $10 \%$ & EU middle $40 \%$ & EU bottom $50 \%$ \\
\hline BG & $0.1 \%$ & $0.4 \%$ & $0.7 \%$ & $2 \%$ & $20 \%$ & $78 \%$ \\
\hline $\mathrm{CY}$ & $0.0 \%$ & $0.1 \%$ & $0.1 \%$ & $10 \%$ & $41 \%$ & $49 \%$ \\
\hline $\mathrm{DE}$ & $4.2 \%$ & $10.4 \%$ & $5.8 \%$ & $11 \%$ & $46 \%$ & $43 \%$ \\
\hline DK & $0.3 \%$ & $0.8 \%$ & $0.4 \%$ & $11 \%$ & $46 \%$ & $43 \%$ \\
\hline $\mathrm{EE}$ & $0.1 \%$ & $0.2 \%$ & $0.1 \%$ & $12 \%$ & $40 \%$ & $47 \%$ \\
\hline ES & $0.5 \%$ & $2.9 \%$ & $4.3 \%$ & $3 \%$ & $24 \%$ & $73 \%$ \\
\hline $\mathrm{GR}$ & $1.9 \%$ & $1.7 \%$ & $0.4 \%$ & $28 \%$ & $48 \%$ & $24 \%$ \\
\hline $\mathrm{HR}$ & $0.0 \%$ & $0.1 \%$ & $0.4 \%$ & $1 \%$ & $10 \%$ & $89 \%$ \\
\hline $\mathrm{HU}$ & $0.1 \%$ & $0.2 \%$ & $0.8 \%$ & $2 \%$ & $11 \%$ & $87 \%$ \\
\hline $\mathrm{IE}$ & $0.3 \%$ & $0.7 \%$ & $0.2 \%$ & $18 \%$ & $55 \%$ & $27 \%$ \\
\hline IT & $2.6 \%$ & $5.3 \%$ & $5.1 \%$ & $10 \%$ & $33 \%$ & $57 \%$ \\
\hline LT & $0.1 \%$ & $0.2 \%$ & $0.3 \%$ & $5 \%$ & $25 \%$ & $70 \%$ \\
\hline LU & $0.1 \%$ & $0.1 \%$ & $0.0 \%$ & $36 \%$ & $42 \%$ & $22 \%$ \\
\hline LV & $0.0 \%$ & $0.1 \%$ & $0.2 \%$ & $3 \%$ & $14 \%$ & $83 \%$ \\
\hline MT & $0.0 \%$ & $0.0 \%$ & $0.0 \%$ & $7 \%$ & $27 \%$ & $65 \%$ \\
\hline SK & $0.1 \%$ & $0.3 \%$ & $0.6 \%$ & $3 \%$ & $23 \%$ & $74 \%$ \\
\hline EU total & $18.7 \%$ & $43.1 \%$ & $38.0 \%$ & & & \\
\hline
\end{tabular}

Key: $0.5 \%$ of the EU emissions are linked to the consumption of Belgian households, which are among the EU top $10 \%$. This includes about $11 \%$ of the country's households. Shading represents the magnitude of the EU CF shares.

See Section 2 for country codes.

The expenditure elasticity exceeds 1 among the lowest-expenditure quintiles (Figure 5), suggesting a high inequality in the distribution of land travel, which calls attention to the importance of equity considerations, particularly in car-dependent rural areas. The elasticities drop below 1 among the biggest spenders, reflecting the more basic nature of this category at higher-expenditure levels. These results confirm transport as one of the most unequally distributed and the strongest drivers of the CF of the rich (Oswald et al., 2020; Otto et al., 2019).

The carbon intensity of the EU bottom $5 \%$ of households is about $0.7 \mathrm{kgCO}_{2} \mathrm{eq} / \mathrm{EUR}$. This varies substantially across countries, from $0.3 \mathrm{kgCO}_{2} \mathrm{eq} / \mathrm{EUR}$ in Sweden to $2.0 \mathrm{kgCO}_{2}$ eq/EUR in Estonia. The EU bottom 5\% show disproportionally large shares of basic consumption (Figure 3). The large differences in carbon intensity across countries give rise to substantial variation in consumption levels (SI2).
Food and housing are necessities and are thus associated with much lower expenditure elasticities than other consumption categories. The food elasticity decreases steadily across EU expenditure quintiles from 0.58 to 0.17 among the lowest and the highest quintiles, respectively (Figure 5). In the context of housing, we note a decrease in the elasticity for the middle quintiles, followed by an increase for the highest quintiles. This may reflect increases in dwelling sizes or shifts to single-family houses (Ivanova et al., 2018) and in turn heating and cooling needs among the highest spenders.

\subsection{Carbon footprints and social outcomes}

Figure 6 sheds more light on the interlinkages between consumption and environmental and social outcomes. In line with previously adopted social thresholds (O’Neill et al., 2018), here we 


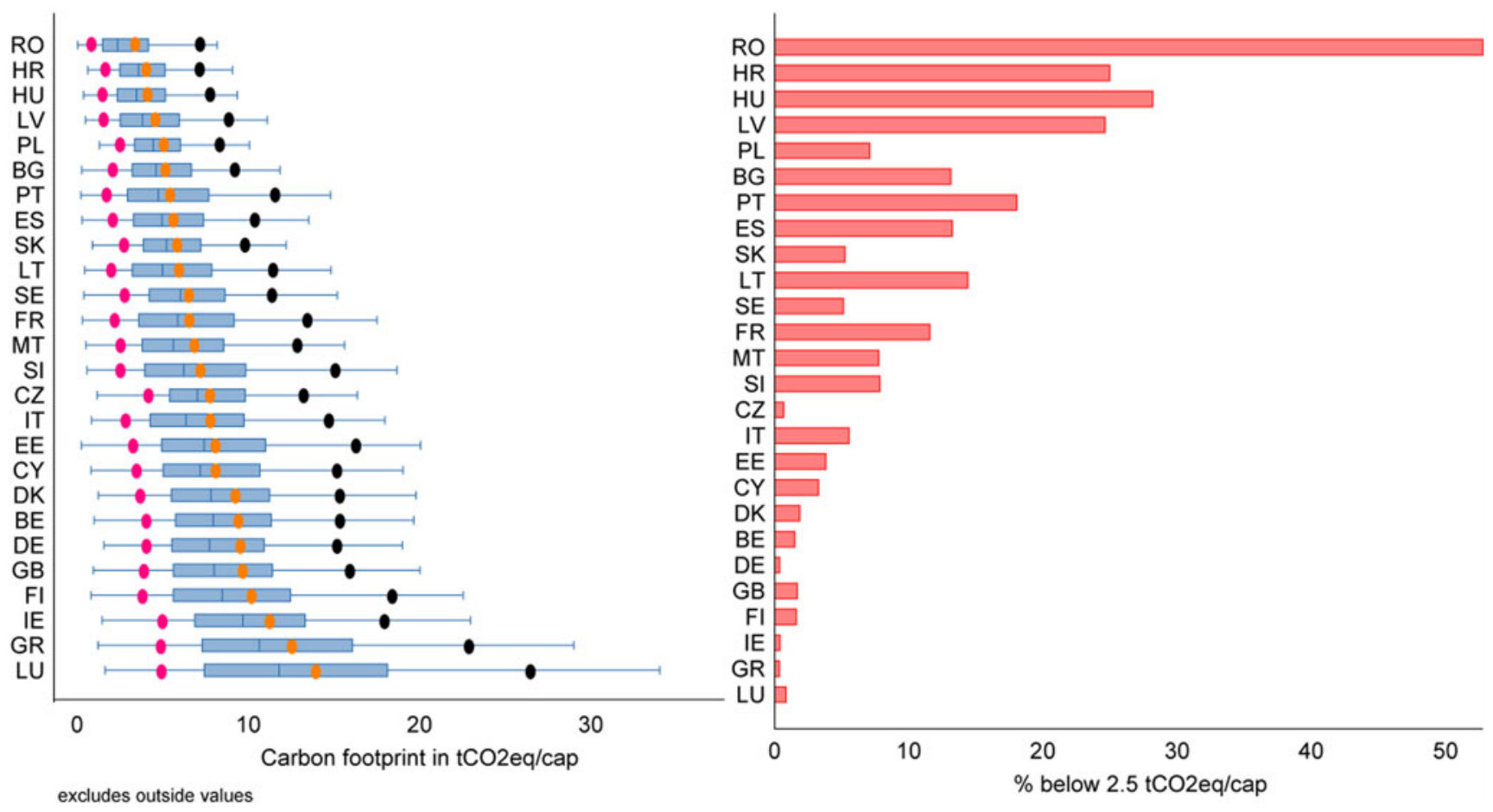

Fig. 2. Distribution of carbon footprints per capita (on the left) and percentage of households below 2.5 tCO ${ }_{2}$ eq/cap (on the right) by country. Countries are ordered by average carbon footprint per capita (orange circles), from the lowest to the highest. The boxes describe 25 th percentiles (left hinge), median and 75 th percentiles (right hinge), and the whiskers describe the minimum and the maximum in the absence of outside values. The pink and grey circles describe the 10th and 90th percentiles in each country, respectively. See Section 2 for country codes.

explore desirable social outcomes such as income, access to energy, employment and nutrition. The graphs depict a wide range of socially desirable outcomes at the same level of CFs.

Income and CFs are strongly positively correlated, as highlighted by prior studies (Baiocchi et al., 2010; Ivanova et al., 2017; Kerkhof et al., 2009; Zhang et al., 2015), with a correlation coefficient of 0.65 for the whole of the EU. Figure 6 depicts several country clusters with varying slopes. The cluster with the steepest slope represent countries such as Estonia and Bulgaria, characterized by relatively low income/consumption levels and high carbon intensities per level of income. The middle cluster captures countries such as Greece and Czech Republic, with moderate carbon intensity and higher income levels. The cluster with the flattest slope consists of the countries with the highest income levels and lowest carbon intensities, such as Denmark and France. Figure 6 displays a wide variation of CFs at fixed incomes, pointing to the countries with the highest carbon efficiency per income level.

Similarly, there is a positive association between the CF and education (as previously suggested; Ivanova et al., 2017), with a correlation coefficient of 0.54 for the EU. Yet, similarly to income, there is wide variation in CFs across countries at similar education levels. A positive, although weaker, association between CFs and nutrition is noted as well, with a correlation coefficient of 0.35 for the EU. We also note a negative correlation between CFs and risk of (fuel) poverty and social exclusion, as well as a weak negative correlation between CFs and living on unemployment benefits, with a coefficient of -0.22 .

Figure 6 depicts associations and should not be interpreted as low emissions causing social challenges or vice versa. Consumption is at the root of these strong associations. Consumption of certain material goods such as food and housing is necessary for the satisfaction of material and human needs
(Jackson, 2005), such as subsistence and protection and decent living standards (Rao \& Min, 2018). The decarbonization of these key material goods remains a challenge for sustainability.

\section{Discussion}

\subsection{The distribution of CFS}

Here, we aim to inform EU, national and regional sustainability efforts through providing a distributional perspective on GHG emissions. Only about $5 \%$ of the EU households conform to climate targets, with CFs below $2.5 \mathrm{tCO}_{2} \mathrm{eq} / \mathrm{cap}$. Our results are in agreement with prior evidence (Bjørn et al., 2018; O'Neill et al., 2018) that substantial decarbonization of consumption is needed to ensure a good life within planetary boundaries. With an average $\mathrm{CF}$ in Europe of $7.5 \mathrm{tCO}_{2} \mathrm{eq} / \mathrm{cap}$ (Ivanova et al., 2020), there is a need to reduce the GHG intensity of consumption by a factor of 3 or more to meet climate targets (Bjørn et al., 2018).

The EU top $1 \%$ emit $55 \mathrm{tCO}_{2} \mathrm{eq} / \mathrm{cap}$ on average, more than 22 times the 2.5-tonne target. Aviation particularly stands out, with a substantial carbon contribution and the highest expenditure elasticities for the highest emitters. The EU top $1 \%$ of households have an average CF share associated with air travel of $41 \%$, making air travel the consumption category with the highest carbon contribution among the top emitters. Package holidays and air transport are luxury items with high energy intensity (Oswald et al., 2020); at the same time, they receive extremely low policy attention, with only $1 \%$ of policies targeting aviation (Dubois et al., 2019). This lack of policy focus on high-carbon polluting activities of high-income actors - who have both high responsibility and capacity for climate change mitigation - raises substantial ethical and equity concerns. 

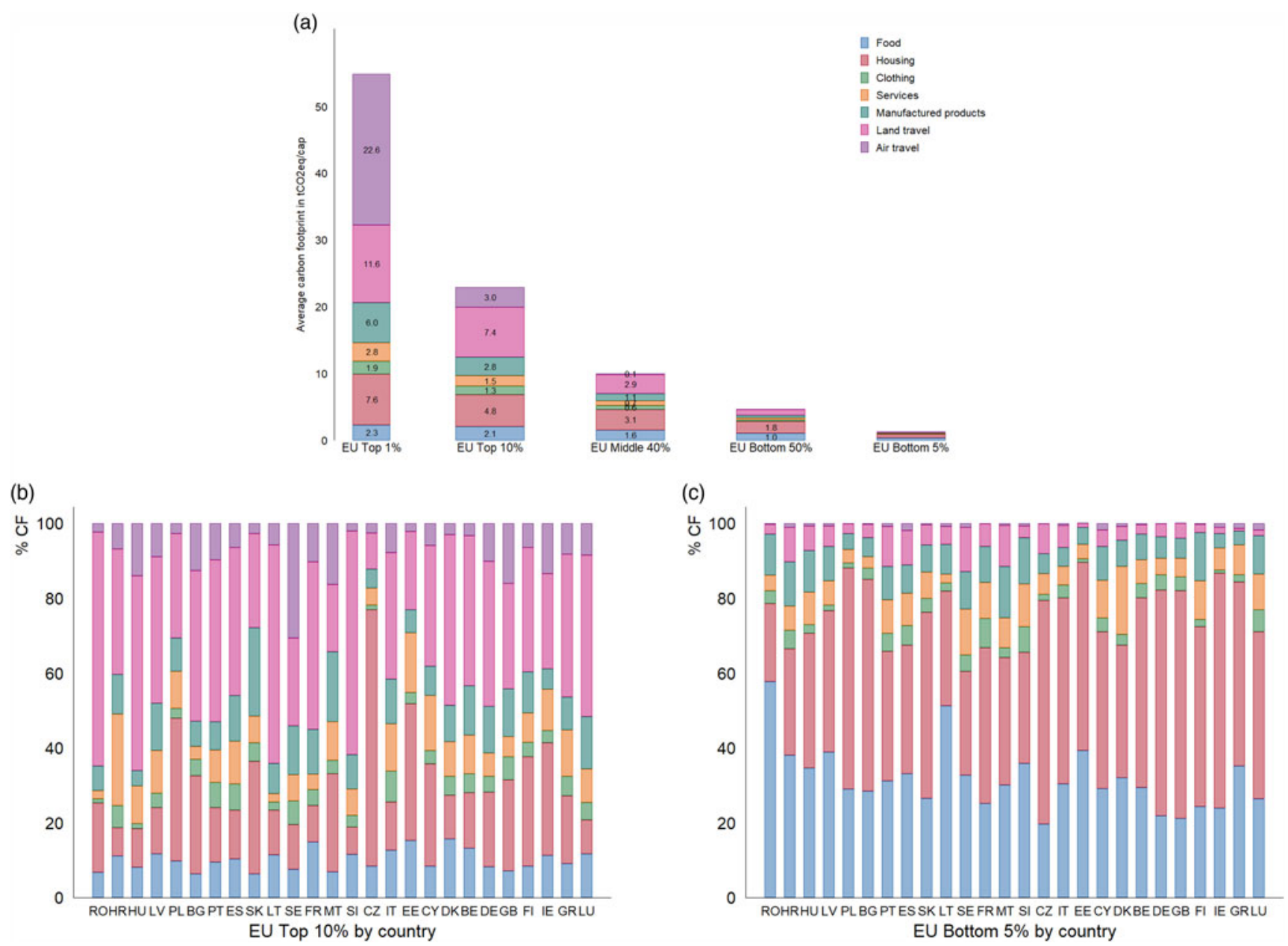

Fig. 3. Average carbon footprint (CF) distribution by consumption category in the European Union (EU) (top). The bottom graph depicts the average CF shares by consumption category and countries of EU top $10 \%$ emitters on the left (with CF $>15 \mathrm{tCO}_{2} \mathrm{eq} / \mathrm{cap}$ ) and EU bottom $5 \%$ of emitters on the right (with CF $<2.5 \mathrm{tCO}{ }_{2} \mathrm{eq} / \mathrm{cap}$ ). See SI4 for country averages. EU household weights applied. See Section 2 for country codes.

Land travel drives $21 \%$ and $32 \%$ of the average CF of the EU top $1 \%$ and top $10 \%$ of households, respectively. Radical emission reductions in this category require decreases in the number of vehicles and travel distance and the shift to low-carbon transport modes (Ivanova et al., 2020). Research on car dependence exposes the difficulty of moving away from a car-dominated, high-carbon transport system and draws attention to the political-economic factors underpinning that dependence (Mattioli et al., 2020). Moreover, the high expenditure share on land travel among the lowest EU expenditure quintile (20\%) is alarming, with relative importance below only basic needs such as food and housing. In Organisation for Economic Co-operation and Development (OECD) countries, the need satisfaction and social inclusion are dependent on car use and ownership, especially in suburban and peri-urban areas built on the assumption of near-universal car access (Mattioli et al., 2020). These results, as well as recent events (e.g., the yellow vest movement in France; Le Monde, 2018), call attention to the importance of equity considerations in transport policy.

Important infrastructural, institutional and behavioural lockins (Seto et al., 2016) and powerful forces of highly profitable (fossil fuel) industries (Fuchs et al., 2016; Roberts et al., 2020) constrain the transition to a low-carbon society. Giving further attention to the ways in which to overcome social and political barriers to low-carbon consumption patterns and living is key (Ivanova et al., 2020; Mattioli et al., 2020; Roberts et al., 2020).

\subsection{Social outcomes and policy recommendations}

This article complements prior cross-country analyses of biophysical boundaries and social thresholds (O’Neill et al., 2018) with within-country perspectives in the EU. We explore the distribution of CFs relative to multidimensional social indicators focusing on income, education, health and living conditions, allowing for a broader measurement of poverty and equity and comparisons across the Sustainable Development Goals (Rao et al., 2017). We observe wide ranges in income, education, nutrition, employment and poverty for the same levels of CFs, highlighting successful cases of low-carbon contribution and high levels of social well-being, as well as high-carbon, low-well-being cases that need further attention (Roberts et al., 2020). Ensuring decent levels of physical requirements (e.g., nutrition, shelter) and social requirements (e.g., communications, mobility) (Rao \& Baer, 2012; Rao \& Min, 2018) for well-being should be a key consideration in the design of a fair climate policy.

More attention on equitable well-being is expected to enable gains in well-being that are compatible with the radical GHG emission reductions needed (Roberts et al., 2020). A 

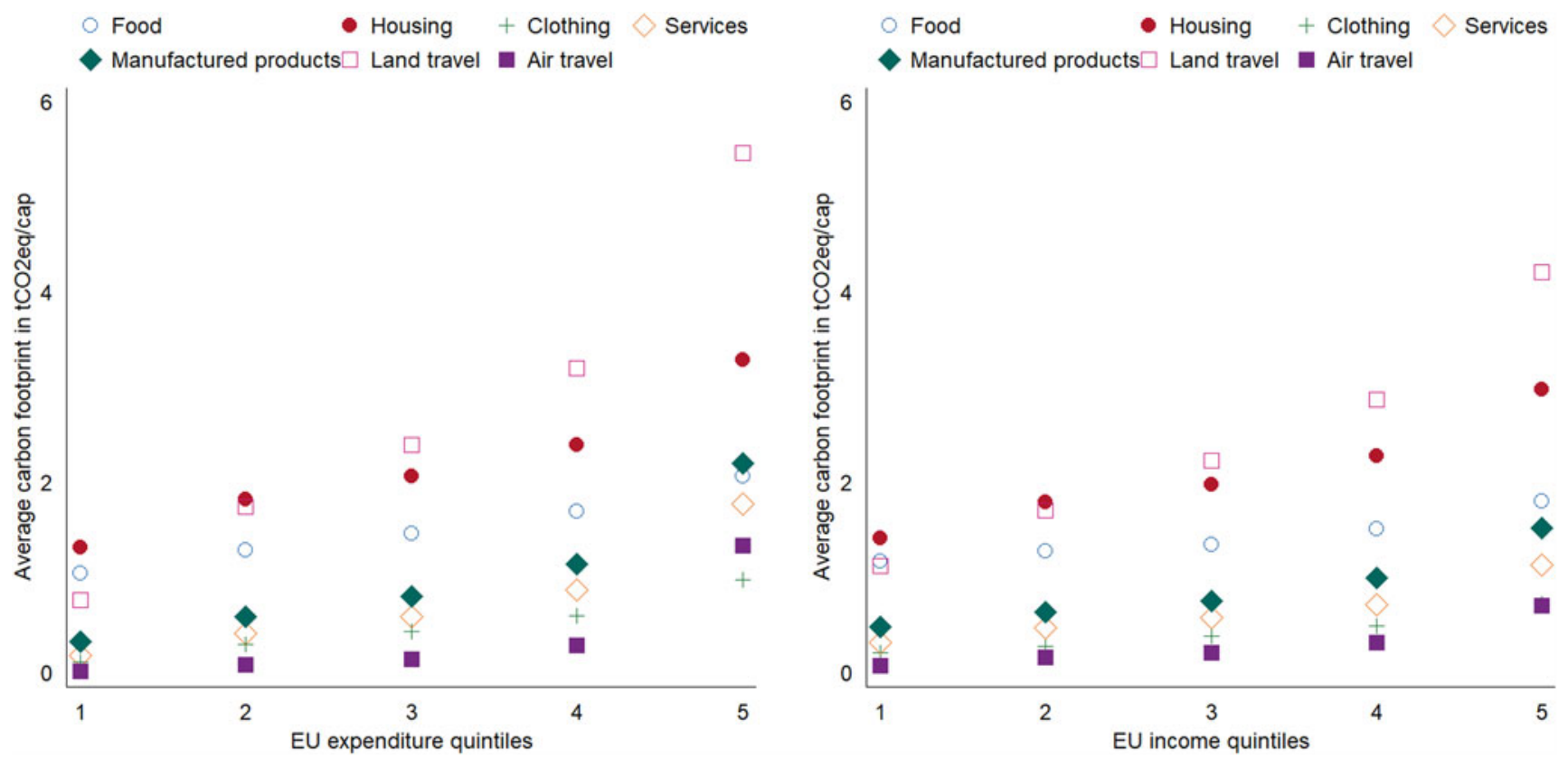

Fig. 4. Average carbon footprint distribution by expenditure quintile (EQ; on the left) and by income quintile (on the right) in the European Union (EU). EQ1 contains households with annual expenditure levels below 6300 EUR in basic prices; 6300 EUR < EQ2 < 9300; 9300 EUR < EQ3<12,800; 12,800 EUR < EQ4<18,700; EQ5 > 18,700 EUR. EU household weights applied.

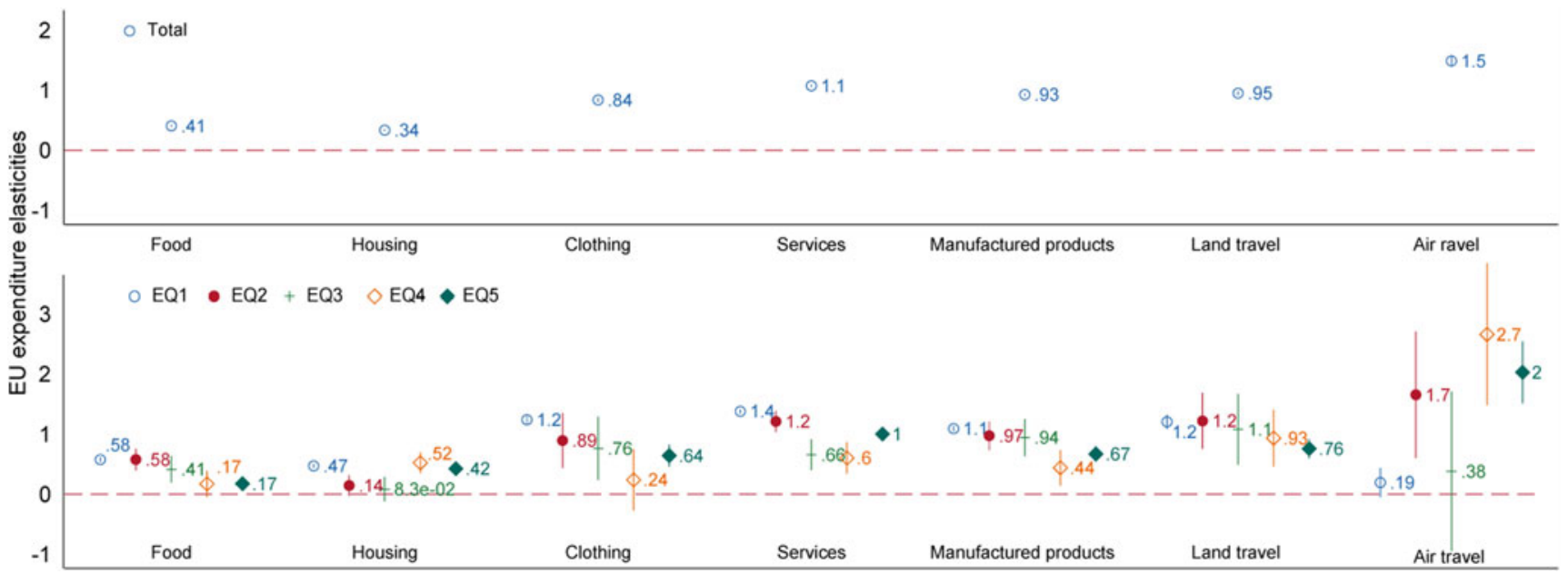

Fig. 5. European Union (EU) expenditure elasticities by consumption category (top) and by consumption category and expenditure quintile combined (bottom). Dependent variable $=\log$ of expenditure in a certain category; independent variable =log of total expenditure. See SI3 for analysis by country. EU household weights applied. See Section 2 for country codes.

comprehensive analysis of the dynamics of the distributional impacts of climate policies and climate change impacts on various household groups is needed in order to inform mitigation and adaptation policies (Rao et al., 2017), capturing household heterogeneity in consumption, income and well-being indicators. The distributional perspective within countries and regions provides an additional monitoring base, and thus a more complete picture of the beneficiaries of various actions and policies (Cullenward et al., 2016; Roberts et al., 2020; Steininger et al., 2016).

Furthermore, there is robust evidence that overconsumption and materialistic practices are not only damaging for the environment, but may also reduce psychological well-being (Brown \&
Kasser, 2005; Jackson, 2005). In order to reduce trade-offs between social and environmental goals, policies should target changes in higher-order need satisfiers, such as social structures and practices, and reimagine forms of need satisfaction within environmental constraints (Mattioli, 2016). Redesigning consumption practices (Ivanova et al., 2020), public spaces and social structures through voluntary simplicity (Jackson, 2005; Vita et al., 2020) and sharing (Ivanova \& Büchs, 2020) may reconcile lower carbon emissions and higher well-being. Collective solutions and investment in social infrastructure (see universal basic services; Coote et al., 2019) hold potential to deliver the social services necessary for human well-being in coherence 
(a) $\cdot \mathrm{BE} \cdot \mathrm{BG} \cdot \mathrm{CY} \cdot \mathrm{CZ} \cdot \mathrm{DE} \cdot \mathrm{DK} \cdot \mathrm{EE} \cdot \mathrm{ES} \cdot \mathrm{FI} \cdot \mathrm{FR} \cdot \mathrm{GB} \cdot \mathrm{GR} \cdot \mathrm{HR}$
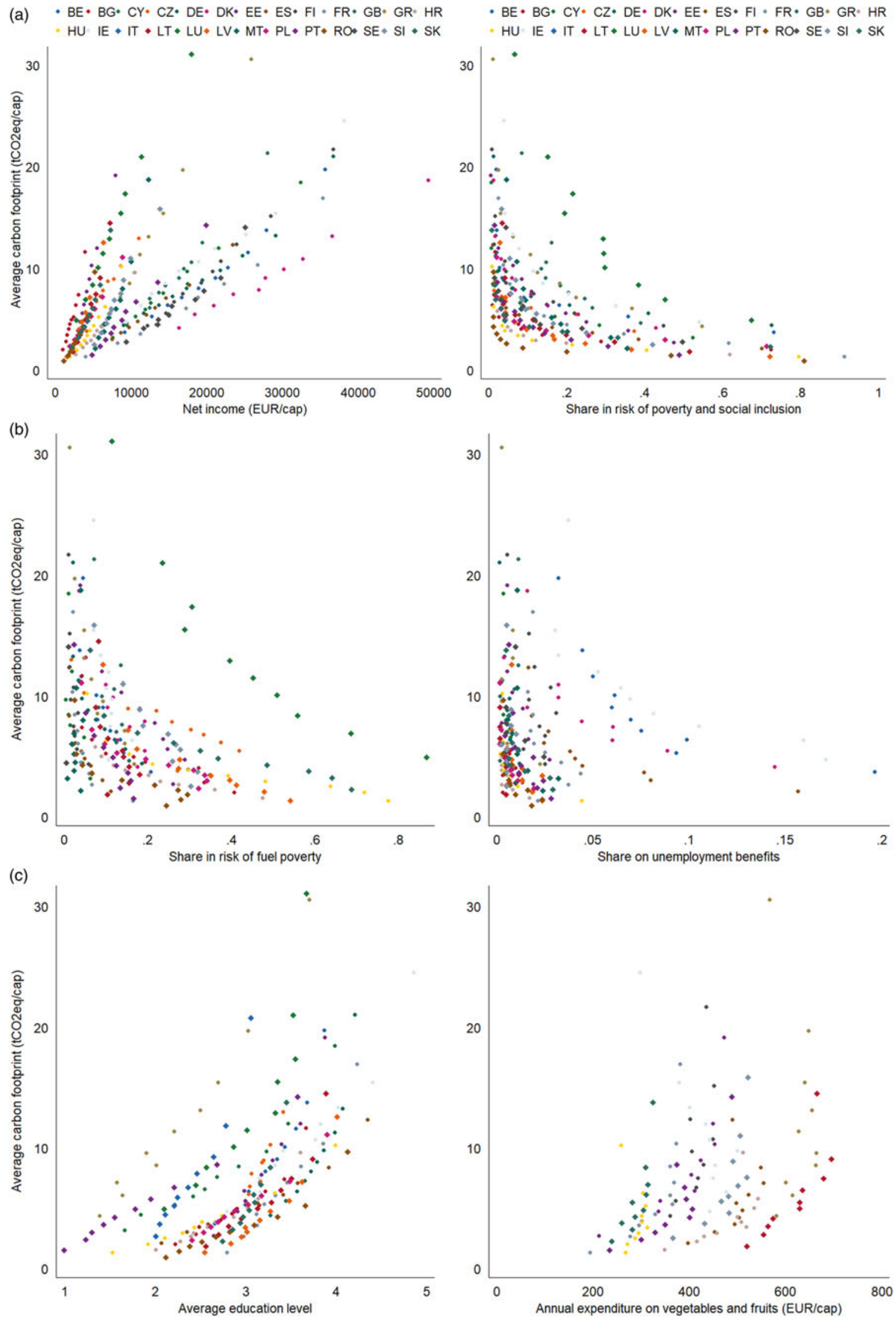

Fig. 6. Average carbon footprints and social outcomes by expenditure decile and country. The shares on the $x$-axes vary from 0 to 1 , corresponding to the range from $0 \%$ to $100 \%$. See Section 2 for country codes. 
with the principles of equity, efficiency, solidarity and sustainability (Coote et al., 2019).

\subsection{Limitations}

The Eurostat HBSs are largely harmonized; however, differences remain in the designs, definitions and procedures. The size of the sampling error depends on the sample size (Eurostat, 2015), and the actual sample sizes are larger than the effective sample sizes for all countries except for Czech Republic and Sweden, where differences are within 10\% (SI1). Certain groups of households may be difficult to access or disproportionately affected by non-response (Eurostat, 2015). In particular, the group of the super-rich may be underrepresented, with countries such as Germany excluding households with a monthly net income higher than $€ 18,000$ (Eurostat, 2015).

Consumption categories may be under- and over-reported given the mode of data collection (Eurostat, 2015). Certain products may be under-reported deliberately as more 'sensitive', or unintentionally due to recall problems (Bee et al., 2012; Eurostat, 2015). Differences in expenditure may also be relatively large for infrequent purchases (e.g., private vehicles, non-work and irregular travel; Clarke et al., 1981; Ivanova et al., 2018; Minnen et al., 2015), resulting in artificial variation among households and elevated standard deviations (Eurostat, 2015; Gill \& Moeller, 2018). The tourism and transport sectors may be associated with higher uncertainty due to residents' spending abroad (Ivanova et al., 2017; Usubiaga \& Acosta-Fernández, 2015). Our footprints focus on household consumption and thus exclude government consumption and investment, which contribute to roughly $32 \%$ of the EU's total CF (Ivanova et al., 2016).

Household expenditure is used in combination with monetary environmental intensities, which vary by product and country. This probably overestimates the environmental impact of expensive products (and wealthier individuals) and underestimates the impact of cheap products (and less wealthy individuals) (Girod \& De Haan, 2010). Physical consumption data - when such data are available - may be useful in controlling for price differences across income cohorts (Girod \& De Haan, 2010). Some HBSs offered physical data on food consumption (quantities in kilograms/litres), which we used to adjust the CFs across income decile groups. While indeed we calculated higher food prices for higher-income quintiles, the differences between the two approaches were not statistically significant for several of the countries. Since the physical data were only available for food and for some of the EU countries, we did not use them in the analysis.

EXIOBASE provides high product detail, depicting the global economy in 200 product classifications (Wood et al., 2015). However, the product detail may still be insufficient to adequately account for the variation of environmental contributions within the same sector. For example, we could not recognize efforts towards green consumerism (e.g., buying a fuel-efficient car or opting for a green energy provider; Gill \& Moeller, 2018). The allocation of emissions from land-use change to specific economic activities is also problematic (Hertwich \& Peters, 2009).

Future work may target some of these limitations by focusing on the environmental and social implications for underrepresented and under-analysed socio-demographic groups. Environmental impact assessment may benefit from higher detail of environmental intensities and physical consumption data collected through the HBSs.

\section{Conclusions}

The EU has committed to an action programme towards a good life for all within the planetary boundaries (European Commission, 2013). Such actions require mitigation efforts by all actors in society and radical reductions in CFs to meet climate targets. In our analysis of the CF of European households using household-level consumption data, we find significant inequality in the distribution of CFs. The top $10 \%$ of the EU population with the highest CFs contribute more carbon compared to the $50 \%$ of the EU population with the lowest CFs. Only 5\% of the EU households live within a CF target of $2.5 \mathrm{tCO}_{2} \mathrm{eq} / \mathrm{cap}$, while the top $1 \%$ of EU households have CFs of $55 \mathrm{tCO}_{2}$ eq/cap. The households with the highest CFs are by and large the households with the highest levels of income and expenditure. Even more so, we find the contributions of land and air transport to be disproportionally large among the top emitters. As land transport and, even more so, air transport are both highly carbon intensive and highly elastic, we would argue that significantly more needs to be done in these domains. Action here is likely to affect those with the highest footprints, incomes and expenditures most, but impacts on low-income groups are also key, as they have significant expenditure shares on land transport. Finally, we analyse the range in CFs in comparison to levels of social outcomes, pointing to the possibility of mitigating climate change while achieving high well-being. Further attention is needed to limit potential trade-offs between climate change mitigation and socially desirable outcomes. The distributional perspective presented in this study brings to the surface remaining key challenges to meet both environmental and social objectives. Exploring the prerequisites for living well within carbon limits is a key focus of our time.

Supplementary information. The supplementary material for this article can be found at https://doi.org/10.1017/sus.2020.12

The supplementary information includes:

- SI1: More details on the household budget survey data and harmonization procedure.

- SI2: More details on the expenditure distributions.

- SI3: Expenditure elasticities by country, consumption category and expenditure quintile.

- SI4: Carbon footprint distribution, including histograms, carbon concentration (Gini) indices, carbon intensities and footprints by consumption category and region.

- SI5: Verification of carbon footprint estimates.

- Supplementary Spreadsheet: country concordances between HBSs and EXIOBASE sectors and concordance from EXIOBASE sectors to consumption categories.

Acknowledgements. We would like to acknowledge Eurostat as a provider of the HBS data essential for our study and to thank their staff for their great communication and service. We would like to thank Dr Loup Suja-Thauvin for his coding assistance and for always finding a solution. We would also like to thank Dr Kjartan Steen-Olsen for assisting with prior code and routines and Robin Styles for writing assistance. We thank Dr Dominik Wiedenhofer for his valuable feedback on an early draft and Dr Milena Büchs for her assistance with the sample representativeness.

Author contributions. D.I. and R.W. designed the study. D.I. assembled the data and performed the analysis. D.I. and R.W. wrote the manuscript.

Financial support. The study was partially funded by a grant from the Strategic Research Area on Sustainability at the Norwegian University of Science and Technology (NTNU). D.I. received funding from the UK 
Research and Innovation (UKRI) Energy Programme under the Centre for Research into Energy Demand Solutions (Engineering and Physical Sciences Research Council (EPSRC) award EP/R035288/1).

Conflict of interest. The authors declare no conflict of interest in the submission of this manuscript.

Code availability. Two codes are used in the text: one to generate carbon footprint results (MATLAB) and one to perform the statistical analysis (STATA). Code is available directly from the authors on request.

Data availability. The work uses the EXIOBASE database, which is released as a freely available dataset through www.exiobase.eu. Micro-data from the HBS were acquired through Eurostat. According to the terms of use, we cannot distribute the micro-data and derived intermediate results. The data that support the findings of this study are available from the corresponding author upon reasonable request.

\section{References}

Baiocchi, G., Minx, J. \& Hubacek, K. (2010). The impact of social factors and consumer behaviour on carbon dioxide emissions in the United Kingdom. Journal of Industrial Ecology, 14(1), 50-72.

Bee, A., Meyer, B. D. \& Sullivan, J. X. (2012). The Validity of Consumption Data: Are the Consumer Expenditure Interview and Diary Surveys Informative? NBER Working Paper Series (Working Paper 18309). National Bureau of Economic Research.

Bjørn, A., Kalbar, P., Nygaard, S. E., Kabins, S., Jensen, C. L., Birkved, M., ... Hauschild, M. Z. (2018). Pursuing necessary reductions in embedded GHG emissions of developed nations: will efficiency improvements and changes in consumption get us there? Global Environmental Change, 52, 314-324.

Brown, K. W. \& Kasser, T. (2005). Are psychological and ecological well-being compatible? The role of values, mindfulness, and lifestyle. Social Indicators Research, 74(2), 349-368.

Büchs, M. \& Schnepf, S. V. (2013). Who emits most? Associations between socio-economic factors and UK households' home energy, transport, indirect and total $\mathrm{CO}_{2}$ emissions. Ecological Economics, 90, 114-123.

Chancel, L. \& Piketty, T. (2015). Carbon and Inequality: From Kyoto to Paris. Paris School of Economics.

Clarke, M., Dix, M. \& Jones, P. (1981). Error and uncertainty in travel surveys. Transportation, 10(2), 105-126.

Coote, A., Kasliwal, P. \& Percy, A. (2019). Universal Basic Services: Theory and Practice. IGP Working Paper Series. UCL Institute for Global Prosperity.

Cullenward, D., Wilkerson, J. T., Wara, M. \& Weyant, J. P. (2016). Dynamically estimating the distributional impacts of U.S. climate policy with NEMS: a case study of the Climate Protection Act of 2013. Energy Economics, 55, 303-318.

Di Donato, M., Lomas, P. L. \& Carpintero, Ó. (2015). Metabolism and environmental impacts of household consumption: a review on the assessment, methodology, and drivers. Journal of Industrial Ecology, 19(5), 904-915.

Dubois, G., Sovacool, B., Aall, C., Nilsson, M., Barbier, C., Herrmann, A., ... Sauerborn, R. (2019). It starts at home? Climate policies targeting household consumption and behavioral decisions are key to low-carbon futures. Energy Research and Social Science, 52, 144-158.

European Commission (2013). Living Well, within the Limits of Our Planet: 7th EAP - The New General Union Environment Action Programme to 2020. European Commission.

European Commission (2019). Fruits and vegetables. Retrieved from https://ec. europa.eu/jrc/en/health-knowledge-gateway/promotion-prevention/nutrition/fruit-vegetables

Eurostat (2015). EU Quality report of the Household Budget Surveys 2010. Retrieved from https://ec.europa.eu/eurostat/documents/54431/1966394/ LC142-15EN_HBS_2010_Quality_Report_ver2+July+2015.pdf/fc3c8acac456-49ed-85e4-757d4342015f

Eurostat (2017). People at risk of poverty or social exclusion. Retrieved from https://ec.europa.eu/eurostat/statistics-explained/index.php/

People_at_risk_of_poverty_or_social_exclusion
Fuchs, D., Di Giulio, A., Glaab, K., Lorek, S., Maniates, M., Princen, T. \& Røpke, I. (2016). Power: the missing element in sustainable consumption and absolute reductions research and action. Journal of Cleaner Production, 132, 298-307.

Gill, B. \& Moeller, S. (2018). GHG emissions and the rural-urban divide. A carbon footprint analysis based on the German Official Income and Expenditure Survey. Ecological Economics, 145, 160-169.

Girod, B. \& De Haan, P. (2010). More or better? A model for changes in household greenhouse gas emissions due to higher income. Journal of Industrial Ecology, 14(1), 31-49.

Girod, B., van Vuuren, D. P. \& Hertwich, E. G. (2014). Climate policy through changing consumption choices: Options and obstacles for reducing greenhouse gas emissions. Global Environmental Change, 25(1), 5-15.

Global Carbon Project (2018). Supplemental data of Global Carbon Budget 2018 (Version 1.0) [Data set]. Retrieved from https:/doi.org/10.18160/ gcp-2018

Hertwich, E. \& Peters, G. (2009). Carbon footprint of nations: a global, tradelinked analysis. Environmental Science \& Technology, 43(16), 6414-6420.

Hubacek, K., Baiocchi, G., Feng, K., Muñoz Castillo, R., Sun, L. \& Xue, J. (2017). Global carbon inequality. Energy, Ecology and Environment, 2(6), 361-369.

Isaksen, E. T. \& Narbel, P. A. (2017). A carbon footprint proportional to expenditure - a case for Norway? Ecological Economics, 131, 152-165.

Ivanova, D., Barrett, J., Wiedenhofer, D., Macura, B., Callaghan, M. \& Creutzig, F. (2020). Quantifying the potential for climate change mitigation of consumption options. Environmental Research Letters. https://doi.org/10. 1088/1748-9326/ab8589

Ivanova, D. \& Büchs, M. (2020). Household sharing for carbon and energy reductions: the case of EU countries. Energies, 13(1909), 1-28.

Ivanova, D., Stadler, K., Steen-Olsen, K., Wood, R., Vita, G., Tukker, A. \& Hertwich, E. G. (2016). Environmental impact assessment of household consumption. Journal of Industrial Ecology, 20(3), 526-536.

Ivanova, D., Vita, G., Steen-Olsen, K., Stadler, K., Melo, P. C., Wood, R. \& Hertwich, E. G. (2017). Mapping the carbon footprint of EU regions. Environmental Research Letters, 12, 054013.

Ivanova, D., Vita, G., Wood, R., Lausselet, C., Dumitru, A., Krause, K., ... Hertwich, E. (2018). Carbon mitigation in domains of high consumer lock-in. Global Environmental Change, 52, 117-130.

Jackson, T. (2005). Live better by consuming less? Is there a 'double dividend' in sustainable consumption? Journal of Industrial Ecology, 9(1-2), 19-36.

Kerkhof, A. C., Benders, R. M. J., \& Moll, H. C. (2009). Determinants of variation in household $\mathrm{CO}_{2}$ emissions between and within countries. Energy Policy, 37(4), 1509-1517.

Le Monde (2018). "Gilets jaunes": "Les élites parlent de fin du monde, quand nous, on parle de fin du mois". Retrieved from https://www.lemonde.fr/politique/article/2018/11/24/gilets-jaunes-les-elites-parlent-de-fin-du-mondequand-nous-on-parle-de-fin-du-mois_5387968_823448.html? xtmc $=1$ le_pen_gilets_jaunes\&xtcr $=142$

Masson-Delmotte, V., Zhai, P., Pörtner, H.-O., Roberts, D., Skea, J., Shukla, P. R., ... Waterfield, T. (2018). IPCC Special Report 1.5 - Summary for Policymakers. Intergovernmental Panel on Climate Change.

Mattioli, G. (2016). Transport needs in a climate-constrained world. A novel framework to reconcile social and environmental sustainability in transport. Energy Research and Social Science, 18, 118-128.

Mattioli, G., Roberts, C., Steinberger, J. K. \& Brown, A. (2020). The political economy of car dependence: a systems of provision approach. Energy Research and Social Science, 66, 101486.

Melnikov, N. B., O’Neill, B. C., Dalton, M. G. \& van Ruijven, B. J. (2017). Downscaling heterogeneous household outcomes in dynamic CGE models for energy-economic analysis. Energy Economics, 65, 87-97.

Middlemiss, L. (2017). A critical analysis of the new politics of fuel poverty in England. Critical Social Policy, 37(3), 425-443.

Minnen, J., Glorieux, I., \& van Tienoven, T. P. (2015). Transportation habits: evidence from time diary data. Transportation Research Part A: Policy and Practice, 76, 25-37.

Niamir, L. (2019). Behavioural Climate Change Mitigation: From Individual Energy Choices to Demand-Side Potential. Doctoral thesis. University of Twente. 
O’Neill, D. W., Fanning, A. L., Lamb, W. F. \& Steinberger, J. K. (2018). A good life for all within planetary boundaries. Nature Sustainability, 1(2), 88-95.

Oswald, Y., Owen, A. \& Steinberger, J. K. (2020). Large inequality in international and intranational energy footprints between income groups and across consumption categories. Nature Energy, 5(3), 231-239.

Otto, I. M., Kim, K. M., Dubrovsky, N. \& Lucht, W. (2019). Shift the focus from the super-poor to the super-rich. Nature Climate Change, 9(2), 82-84.

Rai, V. \& Henry, A. D. (2016). Agent-based modelling of consumer energy choices. Nature Climate Change, 6(6), 556-562.

Rao, N. D. \& Baer, P. (2012). 'Decent Living' emissions: a conceptual framework. Sustainability, 4(4), 656-681.

Rao, N. D. \& Min, J. (2018). Decent living standards: material prerequisites for human wellbeing. Social Indicators Research, 138(1), 225-244.

Rao, N. D., Van Ruijven, B. J., Riahi, K. \& Bosetti, V. (2017). Improving poverty and inequality modelling in climate research. Nature Climate Change, 7 (12), 857-862.

Rausch, S., Metcalf, G. E. \& Reilly, J. M. (2011). Distributional impacts of carbon pricing: a general equilibrium approach with micro-data for households. Energy Economics, 33(Suppl. 1), S20-S33.

Roberts, J. T., Steinberger, J. K., Dietz, T., Lamb, W. F., York, R., Jorgenson, A. K., ... Schor, J. B. (2020). Four agendas for research and policy on emissions mitigation and well-being. Global Sustainability, 3, e3.

Seto, K. C., Davis, S. J., Mitchell, R. B., Stokes, E. C., Unruh, G. \& Ürge-Vorsatz, D. (2016). Carbon lock-in: types, causes, and policy implications. Annual Review of Environment and Resources, 41(1), 425-452.

Solomon, S., Qin, D., Manning, M., Marquis, M., Averyt, K., Tignor, M. M. B., ... Chen, Z. (2007). Contribution of Working Group I to the Fourth Assessment Report of the Intergovernmental Panel on Climate Change: Climate change 2007 The Physical Science Basis. Retrieved from http:// www.ipcc.ch/report/ar4/wg1/

Stadler, K., Wood, R., Bulavskaya, T., Södersten, C.-J., Simas, M., Schmidt, S., ... Tukker, A. (2018). EXIOBASE 3: developing a time series of detailed environmentally extended multi-regional input-output tables. Journal of Industrial Ecology, 22(3), 502-515.

Statistics Explained (2019). Concepts for household consumption - comparison between micro and macro approach. Retrieved from https://ec.europa. eu/eurostat/statistics-explained/index.php?title=Concepts_for_household_ consumption_-_comparison_between_micro_and_macro_approach
Steen-Olsen, K., Wood, R. \& Hertwich, E. G. (2016). The carbon footprint of Norwegian household consumption 1999-2012. Journal of Industrial Ecology, 20(3), 582-592.

Steininger, K. W., Lininger, C., Meyer, L. H., Munõz, P. \& Schinko, T. (2016). Multiple carbon accounting to support just and effective climate policies. Nature Climate Change, 6(1), 35-41.

Tukker, A., Bulavskaya, T., Giljum, S., de Koning, A., Lutter, S., Simas, M., ... Wood, R. (2016). Environmental and resource footprints in a global context: Europe's structural deficit in resource endowments. Global Environmental Change, 40, 171-181.

UN (2017). World Population Prospects: The 2017 Revision. Retrieved from https:/www.un.org/development/desa/publications/world-population-prospects-the-2017-revision.html

UNESCO (2012). International Standard Classification of Education ISCED 2011. Retrieved from http://uis.unesco.org/sites/default/files/documents/ international-standard-classification-of-education-isced-2011-en.pdf

Usubiaga, A. \& Acosta-Fernández, J. (2015). Carbon emission accounting in MRIO models: the territory vs. the residence principle. Economic Systems Research, 27(4), 458-477.

Vita, G., Ivanova, D., Dumitru, A., García-mira, R., Carrus, G., Stadler, K., ... Hertwich, E. G. (2020). Happier with less? Members of European environmental grassroots initiatives reconcile lower carbon footprints with higher life satisfaction and income increases. Energy Research \& Social Science, 60, 101329.

Wiedenhofer, D., Guan, D., Liu, Z., Meng, J., Zhang, N. \& Wei, Y.-M. (2016). Unequal household carbon footprints in China. Nature Climate Change, 7, $75-80$.

Wiedenhofer, D., Smetschka, B., Akenji, L., Jalas, M. \& Haberl, H. (2018). Household time use, carbon footprints, and urban form: a review of the potential contributions of everyday living to the $1.5{ }^{\circ} \mathrm{C}$ climate target. Current Opinion in Environmental Sustainability, 30, 7-17.

Wood, R., Stadler, K., Bulavskaya, T., Lutter, S., Giljum, S., de Koning, A., ... Tukker, A. (2015). Global sustainability accounting - developing EXIOBASE for multi-regional footprint analysis. Sustainability (Switzerland), 7(1), 138-163.

Zhang, X., Luo, L. \& Skitmore, M. (2015). Household carbon emission research: an analytical review of measurement, influencing factors and mitigation prospects. Journal of Cleaner Production, 103, 873-883. 